Rasha Y. Al-Darzi

BDS, MSc (Ass. Lec)

Aseel Fadhil yassin

(B.DS, MSc.) (Ass. Lec)

Huda Abdulhadi Al Sarraf

(B.DS, MSc.) (Lec)

\section{The Effect Of Displaced Maxillary Canine On The Arch Perimeters And Arch Length}

\begin{abstract}
الخلاصة

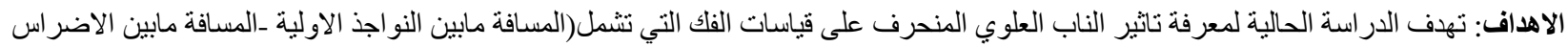

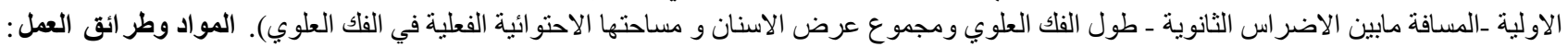

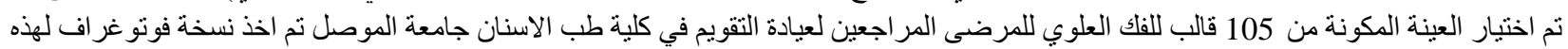

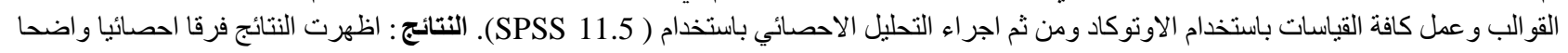

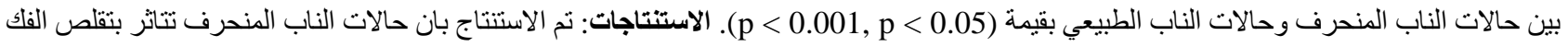
فيما يخص المسافة العرضية بين الاسنان وبان حجم الاسنان في حالات الناب المنحرف يكون الكبر حجما مقارنة بالاسنان في حالات الاناب الابن الطبيعي.
\end{abstract}

\begin{abstract}
Aims: The present study aims to estimate the effect of maxillary canine displacement on the arch measurements including ( inter 1st premolar width, inter1st molar width, inter2nd molar width, arch length, and arch perimeter). Materials and Methods: Maxillary dental study casts of 105 patients attending the orthodontic department of dentistry college, University of Mosul. The casts were photocopied and then all the measurements accomplished with the aid of AutoCAD 2010 software program (Automatic Computer Aided Design). The statistical analysis were done using software package (SPSS 11.5). Results and Discussion: The results showed significant difference among the variables at ( $<<$ $0.001, \mathrm{p}<0.05$ ), the maxillary transverse dimensions were greater in the control group than in the canine displacement group and this may be attributed to that the displaced canine subjects have narrower dental arch than that for the normal subjects, also the results show that the mesiodistal dimensions of maxillary teeth in the canine displacement group were wider in comparison to the control group. Conclusion: The displaced canine position affect the arch width resulting in a narrow transverse arch measurement. In addition, the results of the arch perimeters indicate wider teeth for displaced canine group compared to control group.
\end{abstract}

Key words: displaced canine, AutoCAD program, transverse arch measurement.

Al-Darzi RY, Fadhil yassin A ,Al-Sarraf HA, The Effect Of Displaced Maxillary Canine On The Arch Perimeters And Arch Length. Al-Rafidain Dent J. 2016; 16(1): 84-88.

Received: 11/12/2013 Sent to Referees: 27/1/2014_Accepted for Publication: 6/4/2014

\section{INTRODUCTION}

The ectopic eruption of the maxillary permanent canine may encountered to the subsequent clinical problem like impaction, loss of bone induction, den-tigerous cyst formation and resorption of adjacent teeth. ${ }^{(1,2)}$ The upper canine is regarded to have the longest developmental pe- 
riod of all teeth and its location is extremely far from the occlusal plane and considered to have a tortuous path of eruption. ${ }^{(3)}$ The esthetic and functional importance of upper canine is illustrated vigorously in human dentition when the upper canine guides the mandible in centric relation and ensures that the premolars and molars are subjected to force onto the right axis subsequently it will protect the TMJ. ${ }^{(4)}$ Thus this study aims to understand the effect of canine displacement on the dental arch measurements including inter 1st premolar width, inter1st molar width, inter 2nd molar width, arch length and arch perimeter in a trial to encounter the clinical benefits andattributes.

\section{MATERIALS AND METHODS}

The total sample consisted of 105 subjects with the mean age of 19year range from 13 to 25 years age for both gender, 56 control, and 49 displaced maxillary canine group. One hundred and five maxillary study casts of patients attending the Orthodontic Department of Dentistry, College, the University of Mosul were selected for this study with specific criteria, including: Good quality of Angle Class I molar relation, maxillary dental casts with complete permanent dentition from rightsided second molar to left-sided one, with no dental extraction either unilateral or bilateral buccal canine displacement for the affected group(4), and normal Angle Class I canine relation for the control group. The casts were photocopied using Scanner machine (Epson Perfection 1200U, Model G752A, SEIKO EPSON CORP., SH IOJIRI-SHI, NAGANO-KEN 399-0785, JAPAN), sided by a millimetric scale (ruler) on standard distance from the scanned dental cast Figure (1) ${ }^{(5,6)}$

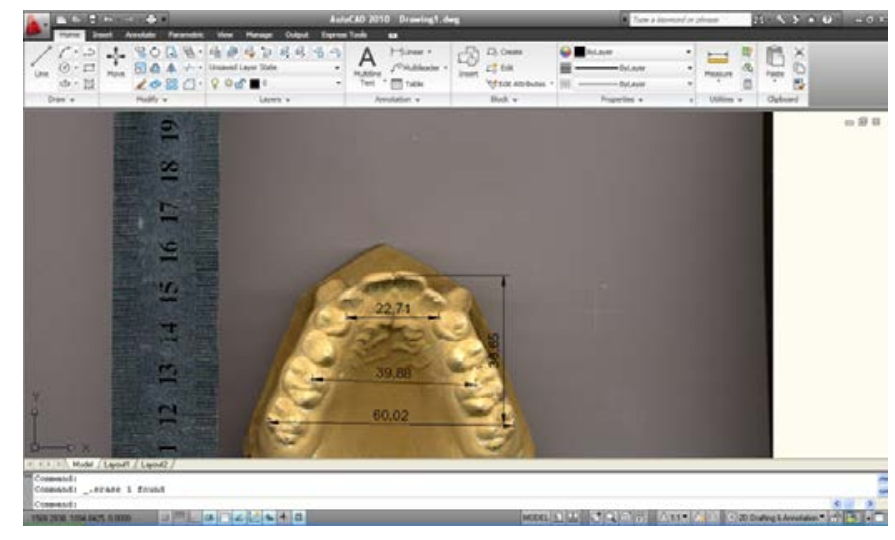

Figure (1): photocopy of the maxillary cast on a standard distance from mellimetric ruler, Analysis of the maxillary dental cast with the aid of Autocad 2010

Then the digital measurment of the present work were accomplished using AutoCAD 2010 software program, (Automatic Computer Aided Design) as demonstrated in Figure (1) starting with the calibration method on the image, there will be specific reference points related to the teeth and marked bilaterally in the maxillary study model for measuring the arch dimensions and as follows:
1. The inter1st premolar distance: the linear distance between the lingual cusps of a 1st bicuspid. ${ }^{(8)}$

2. The Inter 1st molar distance: The linear distance between mesio-lingual cusp of the 1st molars on the right and left sides of the arch. ${ }^{(8)}$

3. Inter 2nd molar distance: the linear distance between the disto-buccal cusp of right and left permanent 2nd molars. ${ }^{(9)}$

4. Mesio-distal width of 1st and 2nd premolars, displaced maxillary canine and the incisor 
teeth for both sides of the arch, the mesio-distal width of each tooth measured from the mesial anatomical contact point to the distal anatomical contact point ${ }^{(8,7)}$

5. Space available of upper dental cast. ${ }^{(7)}$

6. Dental arch length or Total arch length: the vertical distance from the incisal point to the line joining the disto-buccal cusp tip of the 2nd permanent molars. ${ }^{(9)}$

reference points were marked with a pen in order to reduce measurement errors. ${ }^{(5)}$

The dental cast measurements of this study were made at least twice by the same examiner using
AutoCAD program 2010 after three weeks from the original measurements. If the difference between the two measurements appeared, a third reading was made and the different one discarded.

\section{RESULTS}

Descriptive analysis for inter 1st premolar, inter 1st molar, inter 2nd molar, space available, space required, and arch length were accomplished for the control and canine displacement groups with the aid of software package (SPSS 11.5), The mean values, standard error and standard deviation for both groups are given in Table (1)

Table( 1): Descriptive statistics of measurement with comparison between the control and canine displacement group

\begin{tabular}{|c|c|c|c|c|c|c|}
\hline Measurement & Group & No. & Mean & $-\overline{S D}$ & t-value & $p$ value \\
\hline \multirow[b]{2}{*}{$\begin{array}{c}\text { Inter1 } 1^{\text {st }} \text { pre- } \\
\text { molar mea- } \\
\text { surement }\end{array}$} & Control & 49 & 31.73 & 1.69 & \multirow[b]{2}{*}{9.01} & \multirow[b]{2}{*}{$.000 *$} \\
\hline & Displaced canine & 56 & 27.55 & 2.82 & & \\
\hline \multirow[t]{2}{*}{ Inter $1^{\text {st }}$ molar } & Control & 49 & 41.00 & 2.40 & \multirow{2}{*}{5.47} & \multirow[b]{2}{*}{$.000^{*}$} \\
\hline & Displaced canine & 56 & 38.09 & 2.96 & & \\
\hline \multirow[t]{2}{*}{$\begin{array}{c}\text { Inter } 2^{\text {nd }} \text { mo- } \\
\text { lar }\end{array}$} & Control & 49 & 56.28 & 2.62 & \multirow{2}{*}{2} & \multirow{2}{*}{$.000^{*}$} \\
\hline & Displaced canine & 56 & 55.25 & 2.63 & & \\
\hline \multirow[t]{2}{*}{ Arch length } & Control & 49 & 42.93 & 1.94 & \multirow{2}{*}{2.09} & \multirow{2}{*}{$.048^{* *}$} \\
\hline & Displaced canine & 56 & 41.91 & 2.86 & & \\
\hline \multirow{2}{*}{$\begin{array}{l}\text { Space availa- } \\
\text { ble }\end{array}$} & Control & 49 & 74.85 & 2.91 & \multirow{2}{*}{8.3} & \multirow{2}{*}{$.038 * *$} \\
\hline & Displaced canine & 56 & 69.14 & 3.92 & & \\
\hline \multirow[t]{2}{*}{$\begin{array}{l}\text { Space re- } \\
\text { quired }\end{array}$} & Control & 49 & 73.84 & 2.93 & \multirow{2}{*}{-2.9} & \multirow{2}{*}{$.000 *$} \\
\hline & Displaced canine & 56 & 75.82 & 3.71 & & \\
\hline
\end{tabular}


The independent t-test showed very high significance between the control and canine displacement groups, when the canine displacement groups possess the lower mean values for inter1st premolar, inter1st molar , inter 2nd molar transverse dimensions and space required measurement at $\mathrm{p}$ $<0.001$, also the canine displacement group possessed a significantly low mean value for the arch length and space available measurement at $\mathrm{p}<0.05$.

\section{DICUSSION}

The maxillary inter 1st premolar, inter 1st molar and inter 2nd molar transverse dimensions were greater in the control group than those in the canine displacement group, showing high statistically significant difference at $\mathrm{p}<0.001$ and this completely agrees with the findings of Al-Nimri and Gharaibeh $^{(10)}$ which indicates a narrow arch for the displaced canine group than that for the control group. The results also showed more space available for the teeth in the control group than in the canine displacement group , which agree with Artmann et al" (11) who stated that least available space was found in cases with labial canine displacement. Comparing the space required ( mesiodistal teeth widths ) of canine displacement group with the control group, the study submitted a statistically significant difference illustrating that the teeth in the canine displacement group were wider than the control group. These results disagree with Paschos et al. ${ }^{(12),}$ whom study showed that the teeth in the displaced canine side were narrower than those of the nonaffected side in the same patient. Also, these results disagree with Al-Nimri and Gharaibeh $^{(10)}$ when they found that statistically there were no significant difference concerning the maxillary arch perimeter and the total mesiodistal width. Finally the sig- nificantly lower value for the total arch length of displaced canine groups that may be a subsequent result to the reduced arch perimeter (space available measured from mesial contact points of the maxillary right molar to the mesial contact of the maxillary left molars) which agree Artmann et al. who stated that buccally displaced canine is more commonly related to insufficient arch length. ${ }^{(11)}$

\section{CONCLUSIONS}

The displaced canine position affects the arch width resulting in narrow inter 1st premolar and inter 1st molar and inter 2nd molar dimensions. In addition, the results of the arch perimeters indicate wider teeth for displaced canine group compared to the control group, and finally, the arch length in the displaced canine group showed significant reduction compared to the control group.

\section{REFRENCES}

1. Juri Kurol: Early treatment of tootheruption disturbances. Am J Orthod Dento facial Orthop.2002; 121(6): 588-591.

2.Oliver R, Mannion J, Robinson J. Morphology of the lateral incisor in cases of unilateral impaction of the maxillary canine. Br J Orthod. 1989 ;16(1):9-16.

3. Robert D. and Sandy J. . Orthodontics part. Imapcted Teeth. British dental journal. 2004;196(6): 319-27.

4. Langberg BJ., and Peck S.. Adequacy of maxillary dental arch width in patients with palatally displaced canine. Am J Orthod Dentofacial Orthop. 2000;118(2):220-3

5. Simplício AHM, Souza LA, Sakima MT, Martins JCR, SakimaT. Confiabilidade de xerox de modelos de estudo para o traçado de oclusogramas. Ortodontia. 1995; 28(3):62-7. 
6.Paredes V., Gandia J., and Cibrian R. New, fast, and accurate procedure to calibrate a 2-dimensional digital measurement method; Am J Orthod Dentofacial orthop. 2005;127(4):518-9.

7.Proffit WR, Fields HW and Sarver DM: Contemporary Orthodontics. 4th ed. St. Louis, Mosby Company. 2007; P: 195.

8.Adkins MD, Nanda RS, Currier GF. Arch perimeter changes on rapid palatal expansion. Am J Orthod Dentofacial Orthop . 1990; 97(3):194-9

9. Raberin M., Laumon B., Martinc J., Brunner F. . Dimensions and form of dental arches in subjects with normal occlusions. Am $J$ Orthod Dentofacial Orthop. 1993;104(1): 67-72.
10. Al- Nimri and Al-Gharabi Kazem. Space conditions and dental and occlusal features in patients with palatally impacted maxillary canines. Aetiological study. Eur J Orthod. 2005; 27(5): 461-465. 11. Artmann L, Larsen HJ, Sørensen HB, Christensen IJ, Kjaer I. Differences between dentitions with palatally and labially located maxillary canines observed in incisor width, dental morphology and space conditions Eur J Paediatr Dent. 2010 Jun;11(2):82-6. 12.Paschos E, Huth KC, Fässler H, RudzkiJanson I. Investigation of Maxillary Tooth Sizes in Patients with Palatal Canine Displacement. J Orofac Orthop. 2005; 66(4): 288-98. 